\title{
Pengaruh Unsur-Unsur Customer Experience terhadap Minat Pembelian Kembali (Studi Kasus pada Konsumen Anomali Coffee Ubud)
}

\author{
NI KADEK AYU LILIS UPAYANI, \\ KETUT BUDI SUSRUSA, I GUSTI AYU AGUNG LIES ANGGRENI \\ Program Studi Agribisnis, Fakultas Pertanian, Universitas Udayana \\ J1. PB. Sudirman 80232 Denpasar, Bali \\ Email: lilisupayani19@yahoo.com \\ kbsusrusa@yahoo.com
}

\begin{abstract}
The Influence of Customer Experience on Customer Repurchase Intention (A Case Study on Anomali Coffee Ubud Customers)
\end{abstract}

Coffee shop is one of the culinary business which is growing significantly enough. The Anomaly Coffee is a coffee shop which is located at Jalan Raya Ubud No. 88, Ubud, Bali it prepares different types of coffee and foods as the other coffee shops do. Anomali Coffee it also prepares several supporting facilities which can contribute to the customer experience.Its interior design is unique and provides free wifi. Apart from that, the consumers are provided with the opportunity to brew own coffee. This current study was intended to identify and analyze the influence of the elements of customer experience to repurchase intention. The samples in the current study were taken using the accidental sampling technique.The respondents totaled 60. The data were analyzed using the multiple linear regression method.From the result of the study, it could be concluded that the customer experience could be categorized as good. Based on the result of the partial test, the variables of sense and the relate variable have a significant influence on repurchase intention. Simultaneously, the elements of customer experience which consist of the sense, feel, think, act and relate have a significant influence on repurchase intention at Anomali Coffee customer. The R-square score obtained was $78.8 \%$; the rest was obtained from the other factors which were not investigated in the current study.

Keyword: customer experience, repurchase intention, Anomali Coffee

\section{Pendahuluan}

\subsection{Latar Belakang}

Kesuksesan suatu bisnis memerlukan ide-ide kreatif dari pelaku bisnis itu sendiri. Pelaku bisnis dituntut mampu dalam menciptakan ide-ide kreatif dan inovatif agar dapat memberikan nilai lebih kepada konsumen. Pelaku bisnis harus peka akan persaingan bisnis yang dihadapi. Peka dalam melihat peluang bisnis yang memiliki kemungkinan dapat berkembang di kemudian hari. Salah satu usaha yang terus berkembang dan banyak dilirik adalah usaha di bidang kuliner.

Perkembangan bisnis kuliner di Bali saat ini khususnya di Kabupaten Gianyar semakin berkembang pesat salah satunya di Ubud yang merupakan sentra pariwisata di 
Gianyar. Berdasarkan data Dinas Pariwisata Provinsi Bali(2017),pada tahun 2011 hingga tahun 2015pertumbuhan restoran di Kabupaten Gianyar mengalami peningkatan walaupun pada tahun 2012 mengalami penurunan namun penurunan jumlah restoran tidak signifikan. Semakin banyaknya bisnis kuliner maka semakin kuat pula persaingan yang dihadapi.

Tantangan dalam menghadapi persaingan dan mempertahankan keberlangsungan suatu bisnis, maka perlu untuk merencanakan sasaran-sasaran yang ingin dicapai sehingga dapat menentukan strategi-strategi apa saja yang akan digunakan untuk mengahadapi persaingan tersebut. Sebuah produk harus mampu membangkitkan sensasi dan pengalaman yang akan menumbuhkan minat konsumen untuk melakukan pembelian ulang setalah mendapatkan kepuasan pada sebuah perusahaan (Kusumawati, 2013).

Anomali Coffee adalah sebuah nama besar di industri kopi dalam negeri. Konsistensinya dalam mengembangkan kopi asli Indonesia menjadikannya salah satu gerai kopi nikmat yang memiliki tempat istimewa bagi para pencinta kopi.Anomali Coffee memberikan pengalaman-pengalaman kepada konsumennya, seperti konsumen diberikan kesempatan untuk menyeduh (brew) kopinya sendiri, Anomali Coffee lebih mengambil hati pelanggan, memberikan perhatian yang tulus dan perduli terhadap kebutuhan pelanggan sehingga diharapkan pelanggan puas dengan pelayanan yang diberikan serta Anomali Coffee Ubud.

Menurut Schmitt (dalam Hendarsono, 2013) customer experience adalah sebuah pengalaman, dimana pengalaman-pengalaman tersebut merupakan peristiwa-peristiwa pribadi yang terjadi dikarenakan adanya stimulus tertentu misalnya yang diberikan oleh pihak pemasar sebelum dan sesudah pembelian barang dan jasa. Lima dimensi customer experience meliputi panca indra (sense), perasaan (feel), cara berpikir (think), tindakan (act), dan ikatan (relate). Customer experience yang semakin tinggi dirasakan oleh konsumen jelas akan mempengaruhi kepuasan pelanggan dan secara langsung akan mempengaruhi keinginan konsumen untuk datang kembali.

Berdasarkan uraian di atas maka peneliti tertarik untuk meneliti tentang customer experience dengan mengangkat topik "Pengaruh Unsur-Unsur Customer Experience terhadap Minat Pembelian Kembali (Studi Kasus pada Konsumen Anomali Coffee Ubud)".

\subsection{Rumusan Masalah}

Berdasarkan latar belakang di atas, adapun rumusan masalah yang dapat diambil diantaranya.

1. Bagaimana deskriptif tanggapan responden mengenai unsur-unsur customer experience dan minat pembelian kembali pada konsumen Anomali Coffee Ubud?

2. Bagaimana pengaruh customer experience terhadap minat pembelian kembali pada konsumen Anomali Coffee Ubud?

\subsection{Tujuan Penelitian}

Berdasarkan latar belakang yang telah dikemukakan, maka tujuan penelitian ini adalah sebagai berikut.

1. Mendeskripsikan tanggapan responden mengenai unsur-unsur customer experience dan minat pembelian kembali pada konsumen Anomali Coffee Ubud.

2. Menganalisis pengaruh customer experience terhadap minat pembelian kembali pada konsumen Anomali Coffee Ubud. 


\section{Metode Penelitian}

\subsection{Lokasi dan Waktu Penelitian}

Lokasi penelitian dilaksanakan di Anomali Coffee Jalan Raya Ubud No.88, Petulu, Ubud, Kabupaten Gianyar, Bali pada bulan Maret s.d. Mei 2018. Pemilihan lokasi penelitian ini dilakukan secara sengaja (purposive) karena pada Anomali Coffee merupakan kafe kopi yang menawarkan kopi asli Indonesia yang banyak diminati oleh berbagai kalangan baik wisatawan lokal maupun mancanegara, Anomali Coffee memberikan kesempatan kepada pelanggan yang berkeinginan menyeduh kopinya sendiri, dan Anomali Coffee memiliki letak yang strategis yaitu terletak di Jalan Raya Ubud yang merupakan sentra pariwisata di Bali.

\subsection{Data dan Metode Pengumpulan Data}

Jenis data dalam penelitian ini berupadata kuantitatif dan data kualitatif. Data kuantitatif dalam penelitian ini yaitu data pertumbuhan restoran dan kafe di Kabupaten Gianyar, data jumlah pengunjung Anomali Coffee, dan usia responden sedangkan data kualitatif dalam penelitian ini terdiri dari gambaran umum perusahaan dan identitas responden.Sumber data dalam penelitian ini terdiri dari data primer dan data sekunder. Data primer dalam penelitian ini diperoleh dari hasil wawancara dan penyebaran kuesioner kepada konsumen Anomali Coffee Ubud yang meliputi identitas responden, dan pendapat responden tentang customer experience serta minat pembelian kembali pengunjung Anomali Coffee Ubud, sedangkan data sekunder pada penelitian ini adalah buku-buku pendukung, jurnal, penelitian terdahulu, internet dan Dinas Pariwisata Provinsi Bali yang meliputi data pertumbuhan restoran dan kafe di Kabupaten Gianyar.Metode pengumpulan data yang digunakan adalah observasi, wawancara, kuesioner, dan studi pustaka.

\subsection{Populasi dan Sampel}

Populasi dalam penelitian ini adalah semua orang yang pernah membeli minuman maupun makanan di Anomali Coffee Ubud minimal dua kali pembelian.Secara lebih spesifik sampel yang dipilih adalah konsumen yang melakukan pembelian berulang dan berusia minimal 15 tahun. Jumlah sampelditentukan secara quota sampling sebanyak 60 sampel, dengan teknik pengambilan sampel secara accidental sampling.

\subsection{Variabel Penelitian}

Konsep variabel yang digunakan dalam penelitian ini adalah minat pembelian kembali dan unsur-unsur customer experience. Konsep variabel tersebut kemudian dijabarkan dalam bentuk variabel bebas dan variabel terikat.Variabel terikat dalam penelitian ini adalah minat pembelian kembali. Variabel bebas dalam penelitian ini meliputi panca indra (sense), perasaan (feel), cara berpikir (think), tindakan (act), dan ikatan (relate).

\subsection{Pengujian Instrumen Penelitian}

Pengujian instrumen penelitian yaitu menguji validitas dan reliabilitas. Uji validitas digunakan untuk mengukur sah atau tidak suatu kuesioner. Suatu kuesioner dikatakan valid jika pertanyaan atau pernyataan pada kuesioner mampu 
mengungkapkan sesuatu yang akan diukur oleh kuesioner tersebut Ghozali (2013).Uji reabilitas merupakan alat untuk mengukur suatu kuesioner yang merupakan indikator dari variabel atau konstruk. Suatu kuesioner dikatakan reliabel atau handal jika jawaban seseorang terhadap pernyataan adalah konsisten atau stabil dari waktu ke waktu (Ghozali, 2013).Pengujian validitas dan reabilitas dilakukan dengan menggunakan software SPSS.

\subsection{Teknik Skoring dan Metode MSI (Method of Successive Interval)}

Seluruh variabel memiliki indikator yang kemudian diukur menggunakan skala likert.Skala likert digunakan untuk mengukur sikap, pendapat, dan persepsi seseorang tentang suatu objek atau fenomena tertentu (Siregar, 2012).Setiap jawaban memiliki skor yang berbeda-beda seperti pada Tabel 1 .

Tabel 1.

Skor Tingkat Penilaian

\begin{tabular}{ccc}
\hline Kode & Tingkat penilaian & Skor \\
\hline SS & Sangat Setuju & 5 \\
S & Setuju & 4 \\
CS & Cukup Setuju & 3 \\
TS & Tidak Setuju & 2 \\
STS & Sangat Tidak Setuju & 1 \\
\hline
\end{tabular}

Sumber: Siregar (2012)

Skor masing-masing indikator diajukan beberapa pernyataan untuk masingmasing variabel. Skala pengukuran dalam skoring dibedakan menjadi lima kategori. Kategori pengukurannya adalah sebagai berikut (Narimawati,2007).

Tabel 2.

Kategori Pengukuran

\begin{tabular}{cc}
\hline Rata-rata & Kategori \\
\hline $1,00-1,80$ & Sangat jelek \\
$1,81-2,60$ & Jelek \\
$2,61-3,40$ & Sedang \\
$3,41-4,20$ & Baik \\
$4,21-5,00$ & Sangat baik \\
\hline
\end{tabular}

Sumber: Narimawati (2007)

Pengukuran dengan alat ukur yang menggunakan skala likert atau rating scale menghasilkan data yang memiliki skala ordinal.Data ordinal sebelum dilakukan analisis regresi linear berganda, maka data ordinal ditransformasikan terlebih dahulu menjadi data interval menggunakan metode MSI (Method of Successive Interval). Proses transformasi data ordinal menjadi data interval dalam penelitian ini menggunakan bantuan program komputer yaitu microsoft office excel 2016.

\subsection{Metode Analisis Data}

Metode analisis data yang digunakan dalam penelitian ini adalah analisis deskriptif dan analisis kuantitatif yang terdiri dari uji asumsi klasik, regresi linear berganda, dan uji statistik.

1. Analisis deskriptif

Analisis deskriptif dalam penelitian ini adalah hasil analisis yang 
diinterpretasikan, pendeskripsian tanggapan responden mengenai variabel-variabel dalam penelitian yang dilakukan dengan penggolongan rata-rata skor jawaban responden pada skala yang telah ditetapkan dalam lima ketegori.

2. Analisis kuantitatif

Analisis kuantitatif dalam penelitian ini terdiri dari uji asumsi klasik, regresi linear berganda, dan uji statistik. Analisis kuantitatif diuraikan sebagai berikut:

1) Uji asumsi klasik

Uji asumsi klasik merupakan pengujian asumsi-asumsi statistik yang harus dipenuhi pada analisis regresi linear berganda yang berbasis ordinary least square (OLS). Model regresi ini digunakan agar dapat dijadikan alat estimasi yang tidak bias jika telah memenuhi persyaratan BLUE (Best Linear Unbiased Estimator) yakni data berdistribusi normal, tidak terjadi gejala multikolinearitas dan heteroskedastisitas. Uji asumsi klasik dalam penelitian ini dilakukan dengan menggunakan software SPSS.

2) Analisis regresi linear berganda

Regresi linear berganda adalah analisis regresi yang menjelaskan hubungan antara peubah respon (variabel dependen) dengan faktor-faktor yang mempengaruhi lebih dari satu prediktor (variabel independen). Persamaan modelnya adalah sebagai berikut.

3) Uji statistik

$$
Y=a+b_{1} X_{1}+b_{2} X_{2}+b_{3} X_{3}+b_{4} X_{4}+b_{5} X_{5}+e
$$

Santoso dan Fandy dalam Medikana (2016) menyatakan bahwa untuk memperoleh hasil regresi yang baik, maka suatu model harus memenuhi kriteria statistik yang terdiri dari uji pengaruh secara parsial (uji t), uji pengaruh secara simultan (uji F), dan uji koefisien determinasi $\left(\mathrm{R}^{2}\right)$.

\section{Hasil dan Pembahasan}

\subsection{Karakteristik Responden}

Karakteristik responden berdasarkan jenis kelamin, responden laki-laki dan perempuan yaitu terdapat sebanyak 27 orang atau $45 \%$ responden berjenis kelamin lakilaki dan 37 orang atau 55\% responden berjenis kelamin perempuan. Konsumen Anomali Coffee lebih didominasi oleh perempuan. Mayoritas responden berusia 20 tahun sampai dengan 24 tahun dengan presentase 63,33\%. Mayoritas konsumen kopi saat ini memang kebanyakan dari anak muda yang senang menghabiskan waktu luang. Berdasarkan pekerjaan 46,7\% mayoritas responden bekerja sebagai pelajar/mahasiswa. Perkembangan waktu, konsumen kopi memang kebanyakan dari anak muda khususnya pelajar/mahasiswa dimana sekarang ini anak muda lebih sering untuk mengerjakan tugas atau sekedar menghabiskan waktu luang di Anomali Coffee.Responden yang datang ke Anomali Coffee mayoritas bersama teman yaitu sebanyak 46,7\% hal ini menunjukkan banyaknya responden yang datang bersama teman untuk berkumpul atau bercengkrama sekaligus menikmati hidangan kopi dan suasana di Anomali Coffee.Responden dalam penelitian ini mayoritas berkewarganegaraan Indonesiasebanyak 33 orang atau 55\% karena kebanyakan responden dengan kriteria melakukan pembelian berulang yang ditemui secara langsung di Anomali Coffee berasal dari Indonesia. 


\subsection{Deskriptif Tanggapan Responden Mengenai Unsur-unsur Customer Experience dan Minat Pembelian Kembali pada Konsumen Anomali Coffee Ubud.}

Berdasarkan analisis unsur-unsur customer experience, maka secara keseluruhan tanggapan mengenai customer experience Anomali Coffee adalah sebagai berikut.

Tabel 3.

Tanggapan Responden Mengenai Customer Experience

\begin{tabular}{clcc}
\hline No & \multicolumn{1}{c}{ Variabel } & Rata-rata & Kategori \\
\hline 1 & Panca indra & 4,06 & Baik \\
2 & Perasaan & 4,14 & Baik \\
3 & Cara berpikir & 4,18 & Baik \\
4 & Tindakan & 4,05 & Baik \\
5 & Ikatan & 3,88 & Baik \\
\hline & Total & 4,06 & Baik \\
\hline
\end{tabular}

Sumber: Data primer diolah, 2018

Berdasarkan total nilai rata-rata yaitu sebesar 4,06 maka dapat disimpulkan bahwa customer experience berada pada ketegori baik, artinya bahwa customer experience yang diberikan oleh Anomali Coffee sudah dapat dirasakan pelanggan yang hadir sehingga konsumen merasa nyaman dan ingin kembali lagi untuk melakukan pembelian ulang dihari berikutnya.

Tabel 4.

Tanggapan Responden Mengenai Minat Pembelian Kembali

\begin{tabular}{ccccc}
\hline No & \multicolumn{1}{c}{ Pernyataan } & Jumlah & Rata-rata & Kategori \\
\hline 1 & $\begin{array}{l}\text { Saya merasa puas terhadap pelayanan dan } \\
\text { kualitas yang ditawarkan Anomali Coffee }\end{array}$ & 228 & 3,80 & Baik \\
2 & $\begin{array}{l}\text { Saya berkeinginan melakukan pembelian } \\
\text { kembali di Anomali Coffee }\end{array}$ & 226 & 3,77 & Baik \\
\hline \multicolumn{1}{c}{ Total } & 3,78 & Baik \\
\hline
\end{tabular}

Sumber: data primer diolah, 2018

Rata-rata nilai total tanggapan responden terhadap minat pembelian kembali yang diwakili oleh dua item pernyataan adalah 3,78 dengan kategori baik. Hal ini menunjukkan bahwa minat pembelian kembali pelanggan Anomali Coffee sudah baik. Minat pembelian kembali yang baik mengakibatkan konsumen akan membeli lagi produk/jasa yang sama.

\subsection{Pengaruh Unsur-Unsur Customer Experience terhadap Minat Pembelian Kembali}

1) Hasil uji asumsi klasik

Uji asumsi klasik dalam penelitian ini terdiri dari uji normalitas, uji multikolinearitas, dan uji heteroskedastisitas.

a. Uji normalitas

Uji normalitas dilakukan dengan melihat rasio koefisien skewness dan rasio koefisien kurtosis terhadap standar eror masing-masing koefisien tersebut.Rasio 
skewness sebesar 0,526 dan rasio kurtosis sebesar -2,142. Kedua nilai tersebut berada di antara nilai krisis -2 dan +2 , sehingga dapat disimpulkan bahwa data penelitian ini berdistribusi normal.

b. Uji multikolinearitas

Uji multikolinearitas dilakukan dengan melihat nilai TOL (Tolerance) dan

VIF (Variance Inflation Factor) pada masing-masing variabel bebas.Semua varibel bebas memiliki nilai TOL lebih besar dari 0,10 dan nilai VIF lebih kecil daripada 10. Kesimpulannya bahwa model regresi yang dihasilkan tidak mengandung gejala multikolinieritas.

c. Uji heteroskedastisitas

Uji heteroskedastisitas dilakukan dengan meregresikan semua variabel bebas terhadap nilai mutlak residualnya.Nilai signifikansi semua variabel bebas adalah lebih besar dari nilai alpha $(\alpha=0,05)$. Kesimpulannya model regresi yang dihasilkan tidak mengandung gejala heteroskedastisitas.

2) Hasil regresi linier berganda

Hasil penelitian mengenai faktor-faktor yang mempengaruhi minat pembelian kembali yang diterapkan di Anomali Coffee yang dapat dijelaskan sebagai berikut.

\section{Tabel 5.}

Hasil Analisis Regresi Linear Berganda

\begin{tabular}{lcccc}
\hline \multicolumn{1}{c}{ Variabel } & Koefisien & Std. Eror & t-hitung & Sig. \\
\hline Konstanta & $-3,276$ & 0,701 & $-4,671$ & $0,000^{* *}$ \\
Panca indra $\left(\mathrm{X}_{1}\right)$ & 0,192 & 0,062 & 3,076 & $0,003^{* *}$ \\
Perasaan $\left(\mathrm{X}_{2}\right)$ & 0,104 & 0,071 & 1,454 & $0,152^{\mathrm{NS}}$ \\
Cara berpikir $\left(\mathrm{X}_{3}\right)$ & 0,060 & 0,065 & 0,928 & $0,358^{\mathrm{NS}}$ \\
Tindakan $\left(\mathrm{X}_{4}\right)$ & 0,083 & 0,084 & 0,987 & $0,328^{\mathrm{NS}}$ \\
Ikatan $\left(\mathrm{X}_{5}\right)$ & 0,251 & 0,076 & 3,281 & $0,002^{* *}$ \\
\hline R-kuadrat $\left(\mathrm{R}^{2}\right)=73,8 \%$ & \multicolumn{4}{c}{$\mathrm{R}^{2}$ Disesuaikan $=71,3 \%$} \\
F-hitung $=30,374$ & \multicolumn{4}{c}{-value $=0,000$} \\
\hline
\end{tabular}

Keterangan: $* *=$ Signifikan pada taraf nyata $\alpha=0,05$ NS = Non Signifikan

Sumber: data primer diolah, 2018

Persamaan regresi yang dihasilkan adalah sebagai berikut.

$$
\mathrm{Y}=-3,276+0.192 \mathrm{X}_{1}+0.104 \mathrm{X}_{2}+0.060 \mathrm{X}_{3}+0.083 \mathrm{X}_{4}+0.251 \mathrm{X}_{5}
$$

3) Hasil uji statistik

Hasil regresi yang baik dari suatu model harus memenuhi kriteria statistik yang terdiri dari uji pengaruh secara parsial (uji t), uji pengaruh secara simultan (uji F), dan uji koefisien determinasi $\left(\mathrm{R}^{2}\right)$.

a. Uji pengaruh parsial (uji t)

Berdasarkan pengolahan data dengan menggunakan program SPSS maka dapatdihasilkan output pada Tabel 6berikut.

Tabel 6.

Hasil Uji Parsial (Uji t)

\begin{tabular}{lcc}
\hline \multicolumn{1}{c}{ Variabel } & t-hitung & Sig. \\
\hline Konstanta & $-4,671$ & $0,000^{* *}$ \\
Panca indra $\left(\mathrm{X}_{1}\right)$ & 3,076 & $0,003^{* *}$ \\
Perasaan $\left(\mathrm{X}_{2}\right)$ & 1,454 & $0,152^{\mathrm{NS}}$ \\
Cara berpikir $\left(\mathrm{X}_{3}\right)$ & 0,928 & $0,358^{\mathrm{NS}}$
\end{tabular}




\begin{tabular}{lll}
\multicolumn{1}{c}{ Tindakan $\left(\mathrm{X}_{4}\right)$} & 0,987 & \multicolumn{1}{c}{$0,328^{\mathrm{NS}}$} \\
$\mathrm{Ikatan}\left(\mathrm{X}_{5}\right)$ & 3,281 & $0,002^{* *}$ \\
\hline R-kuadrat $\left(\mathrm{R}^{2}\right)=73,8 \%$ & & $\mathrm{R}^{2}$ Disesuaikan $=71,3 \%$ \\
F-hitung $=30,374$ & & P-value $=0,000$ \\
\hline
\end{tabular}

Keterangan: $* *=$ Signifikan pada taraf nyata $\alpha=0,05$ NS $=$ Non Signifikan

Sumber: Data primer diolah, 2018

Berdasarkan hasil uji pengaruh secara parsial diketahui bahwa masing-masing variabel bebas memiliki pengaruhyang berbeda-beda terhadap minat pembelian kembali.Pengaruhmasing-masing variabel bebas terhadap minat pembelian kembali adalah sebagai berikut.

1. Pengaruh panca indra $\left(\mathrm{X}_{1}\right)$ terhadap minat pembelian kembali

Nilai signifikansi yang diperoleh dari hasil regresi sebesar 0,003 , berarti berarti panca indra $\left(\mathrm{X}_{1}\right)$ secara parsial berpengaruh signifikan terhadap minat pembelian kembali yang diterapkan di Anomali Coffee (Y).Didukung dari penelitian terdahulu oleh Kustini (2007) mengungkapkan panca indra (sense) berpengaruh positif signifikan terhadap customer loyalty di boutique roti Bread Talk. Dapat diartikan bahwa konsumen roti Bread Talk yang loyal selalu memiliki minat untuk membeli produk tersebut kembali. Sehingga semakin tinggi pengaruh sense (panca indra) maka minat beli ulang yang tercipta juga semakin tinggi.

2. Pengaruh perasaan $\left(\mathrm{X}_{2}\right)$ terhadap minat pembelian kembali

Berdasarkan hasil pengujian menunjukkan bahwa perasaansecara parsial tidak berpengaruh secara signifikan terhadap minat pembelian kembali pada taraf nyata $\alpha=5 \%$. Hasil penelitian ini sesuai dengan penelitian Alfian (2016) yang berjudul "Analisis Pengaruh Customer Experience terhadap Minat Beli Ulang pada Wiki Koffie Bandung". Hasil penelitian tersebut menyatakan bahwa perasaan ( feel) tidak berpengaruh secara signifikan terhadap minat beli ulang.

3. Pengaruh cara berpikir $\left(\mathrm{X}_{3}\right)$ terhadap minat pembelian kembali

Secara parsial cara berpikirberpengaruh tidak signifikan terhadap minat pembelian kembali. Hasil tersebut dapat dilihat berdasarkan tingkat signifikansi dari $t_{\text {hitung }}$ sebesar 0,358 yang lebih besar dari $\alpha=5$ persen $(0,05)$. Hasil penelitian ini sesuai dengan penelitian Alfian (2016) yang berjudul "Analisis Pengaruh Customer Experience terhadap Minat Beli Ulang pada Wiki Koffie Bandung”. Hasil penelitian tersebut menyatakan bahwa cara berpikir (think) tidak berpengaruh secara signifikan terhadap minat beli ulang.

4. Pengaruh tindakan $\left(\mathrm{X}_{4}\right)$ terhadap minat pembelian kembali

Tindakansecara parsial berpengaruh tidak signifikan terhadap minat pembelian kembali. Hasil tersebut dapat dilihat berdasarkan tingkat signifikansi dari thitung sebesar 0,328 yang lebih besar dari $\alpha=5$ persen $(0,05)$. Hasil penelitian ini sesuai dengan penelitian Alfian (2016) yang berjudul "Analisis Pengaruh Customer Experience terhadap Minat Beli Ulang pada Wiki Koffie Bandung”. Hasil penelitian tersebut menyatakan bahwa tindakan (act) tidak berpengaruh secara signifikan terhadap minat beli ulang.

5. Pengaruh ikatan $\left(\mathrm{X}_{5}\right)$ terhadap minat pembelian kembali

Berdasarkan output SPSS diperoleh hasil bahwa ikatansecara parsial berpengaruh positif dan signifikan minat pembelian kembali. Hasil tersebut dapat dilihat berdasarkan tingkat signifikansi dari thitung sebesar 0,002 yang lebih kecil dari $\alpha=5$ persen $(0,05)$.Hasil penelitian ini sesuai dengan penelitian Hasran 
(2014) yang berjudul "Pengaruh Customer Experience terhadap Pembelian Ulang Studi Kasus pada Konsumen Warung Hotspot Kopi Kami Kendari". Hasil penelitian tersebut menyatakan bahwa hubungan (relate) berpengaruh secara signifikan terhadap minat beli ulang.

b. Uji pengaruh simultan (Uji F)

Berdasarkan pengolahan data dengan menggunakan program SPSS maka dapat dihasilkan output pada Tabel 7.

Tabel 7.

Hasil Uji Pengaruh Simultan (Uji F)

\begin{tabular}{llccccc}
\hline \multirow{2}{*}{ Model } & $\begin{array}{c}\text { Jumlah } \\
\text { Kuadrat }\end{array}$ & Df & $\begin{array}{c}\text { Rata-rata } \\
\text { Kuadrat }\end{array}$ & F & Sig. \\
\hline \multirow{3}{*}{1} & Regresi & 106,032 & 5 & 21,206 & 30,374 & $0,000^{\mathrm{b}}$ \\
\cline { 3 - 4 } & Residual & 37,701 & 54 & 0,698 & & \\
& Total & 143,733 & 59 & & & \\
\hline
\end{tabular}

Sumber: Data primer diolah, 2018

Berdasarkan output SPSS diperoleh hasil bahwa berarti variabel panca indra $\left(\mathrm{X}_{1}\right)$, perasaan $\left(\mathrm{X}_{2}\right)$, cara berpikir $\left(\mathrm{X}_{3}\right)$, tindakan $\left(\mathrm{X}_{4}\right)$, dan ikatan $\left(\mathrm{X}_{5}\right)$ secara simultan berpengaruh signifikan terhadap minat pembelian kembali yang diterapkan di Anomali Coffee (Y). Hal tersebut dapat dilihat berdasarkan tingkat signifikansi sebesar 0,000 yang lebih kecil dari $\alpha=5$ persen $(0,05)$.

\section{c. Koefisien determinasi $\left(\mathrm{R}^{2}\right)$}

Koefisien determinasi adalah suatu analisis yang digunakan untuk mengetahui pengaruh dari suatu variabel terhadap variabel lainnya. Hasil pengolahan data pada koefisien determinasi adalah sebagai berikut.

Tabel 8.

Hasil Uji Koefisien Determinasi $\left(\mathrm{R}^{2}\right)$

\begin{tabular}{ccccc}
\hline Model & $\mathrm{R}$ & $\mathrm{R}^{2}$ & $\mathrm{R}^{2}$ Disesuaikan & Std. Eror Estimasi \\
\hline 1 & 0,859 & 0,738 & 0,713 & 0,836 \\
\hline
\end{tabular}

Sumber: Data primer diolah, 2018

Nilai koefisien determinasi pada Tabel 8. menunjukkan angka 0,738. Besarnya angka koefisien determinasi $\left(\mathrm{R}^{2}\right)$ 0,738 sama dengan 73,8\%. Angka tersebut mengandung makna bahwa variabel panca indra, perasaan, cara berpikir tindakan, dan ikatanberpengaruh terhadap minat pembelian kembali sebesar 73,8\% sedangkan sisanya sebesar 26,2\% digambarkan oleh variabel lain diluar model yang diuji, dengan demikian terdapat hubungan dan determinasi yang kuat antara variabel bebas terhadap variabel terikat pada penelitian ini.

\section{SimpulandanSaran}

\subsection{Simpulan}

Berdasarkan hasilpenelitian diketahui bahwa customer experience Anomali Coffee termasuk dalam kategori baik dengan pencapaian skor rata-rata sebesar 4,06 yang menunjukkan bahwa customer experience Anomali Coffee sudah baik di mata konsumen. Minat pembelian kembali dengan pencapaian skor rata-rata sebesar 3,78 termasuk dalam kategori baik. Secara parsial hanya dua variabel yang berpengaruh signifikan terhadap minat pembelian kembali yaitu variabel panca indra (sense) dan 
ikatan (relate). Variabel bebas secara simultan berpengaruh signifikan terhadap minat pembelian kembali.

\subsection{Saran}

Saran yang dapat penulis sampaikan kepada Anomali Coffee adalah perlu melakukan peningkatan customer experience khususnya pada unsur panca indra (sense) seperti memperindah desain interior, serta lagu yang diputar lebih menyesuaikan dengan konsumendan pada unsur ikatan (relate) seperti lebih menonjolkan kepada konsumen bahwa adanya kesempatan menyeduh kopinya sendiriagar lebih menambah minat pembelian kembali konsumen. Selain itu meningkatkan fasilitas-fasilitas pendukung seperti menambah parkiran, menambah stopkontak, dan suhu ruangan yang kurang dingin.

\section{Ucapan Terima Kasih}

Ucapan terimakah penulis tujukan kepada Anomali Coffee serta semua pihak yang telah membantu dalam pelaksanaan penelitian hingga karya ilmiah ini dapat dipublikasikan dalam bentuk e-jurnal.

\section{Daftar Pustaka}

Alfian, Fredrick. 2016. Analisis Pengaruh Customer Experience terhadap Minat Beli Ulang pada Wiki Koffie Bandung. [Jurnal]. Universitas Telkom.

Dinas Pariwisata Provinsi Bali. 2017. Restoran di Provinsi Bali Per Kabupaten/Kota Tahun 2011-2015.

(www.disparda.baliprov.go.id/files/subdomain/disparda/tab_25_dst.xls). Diakses tanggal 18 Desember 2017.

Ghozali, Imam. 2013. Aplikasi Analisis Multivariate dengan Program SPSS. Edisi Ketujuh. Semarang: Badan Penerbit Universitas Diponegoro.

Hasran, Mufasir. 2014. Pengaruh Customer Experienceterhadap Pembelian Ulang Studi Kasus pada Konsumen Warung Hotspot Kopi Kami Kendari. [Jurnal]. Fakultas Ekonomi dan Bisnis Universitas Halu Oleo.

Hendarsono, Gersom dan Sugiono Sugiharto. 2013. Analisis Pengaruh Experiential Marketing terhadap Minat Beli Ulang Konsumen Café Buntos 99 Sidoarjo [Jurnal]. Manajemen Pemasaran.

Kustini. 2007. Penerapan Experiential Marketing. [Jurnal]. UPN Veteran Jawa Timur Kusumawati, Ika. 2013. Analisis Pengaruh Customer Experience terhadap Minat Beli Ulang (Studi Kasus Pada Konsumen Restoran the House of Raminten Yogyakarta). [Jurnal].Jurusan Manajemen Fakultas Ekonomika dan Bisnis Universitas Diponegoro.

Medikana, Ari. 2016. Faktor-faktor yang Mempengaruhi Permintaan Buah Salak Bali (Salacca Zalacca var. ambonensi) Oleh Rumah Tangga di Kota Denpasar,

Provinsi Bali [Skripsi]. Denpasar: Program Studi Agribisnis Fakultas Pertanian Universitas Udayana.

Narimawati, Umi. 2007. Riset Manajemen Sumber Daya Manusia: Aplikasi Contoh dan Perhitungan. Jakarta: Agung Media.

Siregar, Syofian. 2012. Metode Penelitian Kuantitatif. Jakarta: Prenadamedia Group.

Sugiyono, 2008. Metode Penelitian Kuantitatif Kualitatif dan R\&D. Bandung: Alfabeta. 